\title{
134 MATURE MINORS AND REFUSAL OF MEDICAL TREATMENT
}

C Tobin' ${ }^{1}$ Juris Doctor Student, University of Melbourne, Victoria, Australia

10.1136/bmjspcare-2013-000491.134

Background In all Australian states, except South Australia, a minor is able to consent to treatment (provided he or she demonstrates a 'sufficient understanding and intelligence to enable him or her to understand fully' the proposed medical treatment ${ }^{\mathrm{i}}$ ) but not to refuse medical treatment. It has been argued that the law is inconsistent on this matter, that logic and consistency (as well as the modern understanding of the autonomy of the minor) would say that a minor who is sufficiently mature to consent to treatment should also be mature enough to refuse it, even if this causes the minor to die or suffer adverse consequences.

Aim An analysis of whether Australian law should allow a minor to refuse medical treatment.

Method The analysis of case law, legislation and academic opinion expressed in both legal and ethical journals.

Results As this is not an empirical study but a study of legal and ethical argument, the results are canvassed in the Discussion.

Discussion This paper canvasses the arguments for and against the recognition of such a right. It argues that the refusal of medical treatment is not merely the converse of the right to consent to medical treatment: refusal requires a higher level of maturity, in particular an appreciation of the long-term consequences of a decision to refuse treatment.

Conclusion This study concludes that Australian law should not recognise a right of the mature minor to refuse medical treatment.

${ }^{i}$ Gillick v West Norflock AHA (Gillick's case) [1986] AC 112 at 189 (HL); adopted into Australian law in Secretary, Department of Health and Community Services v JWB (Marion's Case) (1992) 106 ALR 385. 